\title{
Perception of Self-Efficacy and Health-Related Behavior in Context of Taekwon-Do Sport Camps
}

\author{
Dorota Ortenburger (D), Jacek Wąsik *(D) and Dariusz Mosler (D) \\ Department of Kinesiology and Health Prevention, Jan Dlugosz University of Czestochowa, \\ 42-200 Częstochowa, Poland; d.ortenburger@ujd.edu.pl (D.O.); d.mosler@ujd.edu.pl (D.M.) \\ * Correspondence: j.wasik@ujd.edu.pl
}

Citation: Ortenburger, D.; Wassik, J.; Mosler, D. Perception of Self-Efficacy and Health-Related Behavior in Context of Taekwon-Do Sport Camps. Sustainability 2021, 13, 4645 .

https://doi.org/10.3390/su13094645

Academic Editors: Wojciech

J. Cynarski and Marc A. Rosen

Received: 23 March 2021

Accepted: 20 April 2021

Published: 22 April 2021

Publisher's Note: MDPI stays neutral with regard to jurisdictional claims in published maps and institutional affiliations.

Copyright: (c) 2021 by the authors. Licensee MDPI, Basel, Switzerland. This article is an open access article distributed under the terms and conditions of the Creative Commons Attribution (CC BY) license (https:// creativecommons.org/licenses/by/ $4.0 /)$.

\begin{abstract}
Background: The aim of this paper is to expand the knowledge on the subject matter of the relations between behavior that is geared towards health and the feeling of effectiveness in the context of martial arts tourism in the form of Taekwon-do training summer camps. Method: The research encompassed 58 people (32 men and 26 women) who train Taekwon-do (ITF) (aged: $26.36 \pm 8.97$; scope: $18-45$ years of age). The measurement of the feeling of effectiveness and healthy behavior was conducted by means of standardized tools, including the General Self-Efficacy Scale. Results: The analyzed fighters who participated in the research in the majority of the sports meetings declared a higher level of the feeling of effectiveness $(p<0.001)$. Through cluster analysis emerged two groups, with a significant difference between self-efficacy (mean value of 20.05 points in contrast to 33.93 points in the second group). The group with higher psychological indices values attended a higher amount of summer camps during their practice history (at least two camps attended in the second cluster). Conclusion: Sports tourism connected with martial arts, as exemplified by training groups (professionally organized training camps) of Taekwon-do (ITF), is connected with the increased feeling of personal effectiveness, while also serving the enhancement of psycho-physical health, well-being, and the development of social skills.
\end{abstract}

Keywords: self-efficacy; health-related behavior; Taekwon-do; sport camps

\section{Introduction}

Health aspects and conditions refer to biological, social, and psychological spheres [1] The salutogenic approach highlights the crucial role of preserving health instead of solely treating illness when it occurs; therefore, more emphasis is put into the psychological and social aspects of maintaining health in contrast to the conventional biological domination model [2].

Physical activity behavior is a complex and multidimensional phenomenon. For its analysis, transdisciplinary biopsychosocial approaches yield great potential [3]. Therefore, a proper lifestyle is a key factor in maintaining health. This strategy consists of a proper diet and eating habits, sufficient amount of sleep, satisfaction with the social role, and good free time management, alongside optimal physical activity [4].

One of the wholesome types of physical activity is that of martial arts due to the stimulation of the whole body during training. Some martial arts connect traditional and sport aspects, such as Taekwon-do or Karate. Many researchers indicate in their studies that martial arts should not be perceived as a self-defense system only, but also as a leisure activity and strong stimuli for psychophysical development [5-7] and therapy [8,9].

There are studies that support health-related aspects of martial arts practice, which can be used in some medical conditions; for example, with the higher risk of a fall due to the lack of proper static and dynamic balance [10]. Regular practice of a variety of tasks could bring back and increase the sense of one's body control. This happens because of the improvement in the body feedback, information processing, and somatognosis with 
proprioception. This results in the improvement of the static and dynamic balance [11-14]. A healthy lifestyle due to practice and competition in martial arts is helpful in building greater possibilities of action, which are beneficial for self-perceived efficiency [15].

From the perspective of martial arts, the biopsychosocial concept of human health and development is included in the General Theory of Fighting Arts (GTFA). This theory extends the understanding of martial arts as sport activity by adding humanistic aspects, and therefore the cultural and social context of the practice. Overall, GTFA is a sum of humanistic, social, and cultural issues with philosophical, cultural, and biological ones extended by sport science with an emphasis on martial art sciences [16].

Additional forms of leisure time activity, such as organized seminars and tourist camps for Taekwon-do, elevate the training intensity level for a short period of time. The great effort of the participants during such activities does not guarantee future success during a competition but are linked to such a possibility. The benefits only exceed the motor improvement. During the increased physical activity in leisure time, the mental capacities of an athlete could be boosted due to the improvement of focus and awareness. In the wider perspective, Taekwon-do camps with a skilled supervisor are also connected with meeting new peers and places, apart from extending the attendants' knowledge about cultural sites in the visited area, as training is mixed with tourism. Therefore, camps are a source of new experiences in various walks of life where tourist aspects are linked to the psychological and sociological components of a health model. During the aforesaid camps, athletes spend most of their time with their masters, which is a different relationship than normal training sessions [17]. This gives them the chance to learn from the examples of lifestyles or social interaction habits from the supervisors [18]. These could be beneficial lessons in life about proper social behavior built on the respect and ethics in the professional field.

The phenomenon of training camps is part of one more aspect of the General Theory of Martial Arts, which was mentioned above. Martial arts tourism is an activity which includes traveling to learn or teach martial arts $[19,20]$. These trips are motivated by practicing, studying, teaching, or promoting martial art [21]. Therefore, activities such as training camps, even though they could not be related to any special place related to martial arts, are special activities with the purpose of practice.

According to the sustainable development concept, there is a constant need for better programs to enhance the proper patterns of human relations for building more harmonious social development. Hence, the aim of this study is to obtain knowledge about the possible relation between health-related behavior and the generalized self-perceived efficiency in the context of martial arts tourism in the form of training summer camps.

\section{Materials and Methods}

\subsection{Subjects}

The analyzed group consisted of 58 Taekwon-do ITF (International Taekwon-do Federation) athletes (32 males and 26 females, mean age of $26.36 \pm 8.97$ years old with ranges from 18 to 45), who belong to Silesian Voivodship (Province) of Poland.

\subsection{Protocol}

The data were collected with the use of standardized psychological tools, previously used in numerous studies and validated as follows:

(1) The General Self-Efficacy Scale (unidimensional) was used to assess the perceived self-efficacy with regard to coping and the adaptation abilities in stressful events and in daily activities. The General Self-Efficacy Scale (GSES) is composed of 10 statements. Internal reliability for the full set of items of GSES was 0.80 Cronbach's alpha [22]. The scale is usually self-administered. Responses (scoring) are made on a 4-point scale. The scale was created to assess the general sense of the perceived self-efficacy with the aim of predicting the level of coping with daily activities, experiences, and hassles. The construct of perceived self-efficacy reflects a self-belief. This is the belief that one can perform a novel or difficult task, or cope with adversity-in various domains 
of functioning. Perceived self-efficacy is an operative construct, i.e., it is related to subsequent behavior and, therefore, is relevant for practice and behavior change [20].

(2) The Health Behavior Inventory (HBI) was used for the evaluation of health-related behavior [22]. Its construction validity was verified by the correlation method with the results of the Multidimensional Health Locus of Control scales by Wallston et al. in 1978 [23]. The Health Behavior Inventory consists of 24 statements used to assess health behavior in four subscales: proper dietary habits $(\mathrm{PDH})$, prophylactic behavior (PB), health-related practices (HRP), and a positive attitude (PA). The overall health behavior score ranges between 24 and 120 points. The higher the score, the higher the level of the health behavior. The internal validity of the Health Behavior Inventory was established based on the Cronbach alpha coefficient, whose value was 0.85 for the overall Inventory and from 0.6 to 0.65 for separate categories [22].

The data gathering process lasted one training season. The study group was composed of athletes from different clubs and cities, who met at the Taekwon-do seminars. The only inclusion criteria were being a member of a Taekwon-do club and be an adult (age over 18 years old).

Additional information (age) was collected with information about number of Taekwondo summer camps that practitioners attended in their lifetime practice.

\subsection{Ethics}

The test protocol met the criteria of Ethical Conduct for Research Involving Humans. All subjects in the study were informed of the testing procedures and voluntarily participated in the data collection.

\subsection{Statistical Analysis}

For all the obtained variables, the mean, variance (SS), and standard deviation (SD) were computed. Moreover, for all the related variables, the Pearson correlation coefficient was calculated, alongside the univariate analysis (ANOVA). The significance level was set at $p<0.05$. For the purpose of taxonomy of the tested people, cluster analysis with the use of the k-means method was used, which is recommended for this type of study [24]. The cluster analysis was referred to as the generalized self-efficacy and health-related behavior. All procedures were computed with the use of Statistica 12 software.

\section{Results}

The tested subjects showed the mean level of the health habits indicator at the level of 84.78. The higher spread of the results is shown by a group of females, with the overall score ranging from 56 to 93 points, while the findings for males spread from 70 to 101 . Despite the different individual extremes, the mean values of the indicator are similar for both groups. In the case of the specific indicator, both males and females showed the highest value of health habits, with a more similar mean score for the remaining items in the Inventory (Table 1). The ANOVA analysis for the specific indicators and overall values did not reveal significant differences between the genders with $p=0.858$.

The Generalized Self-Efficacy (GSE) value increased with the declared number of summer camps that the individuals attended during their practice history (Figure 1). The lower presented value of GSE is 10, while the maximum presented value is close to the maximum possible score of this indicator- 38 of 40 points. The mean value of this indicator is 23.61 . 
Table 1. Descriptive statistics of Health Behavior Inventory variables of participants.

\begin{tabular}{|c|c|c|c|c|c|}
\hline Gender & Health-Related Behavior & Mean & Min & $\operatorname{Max}$ & SD \\
\hline \multirow{5}{*}{ Females } & Proper eating habits & 21.12 & 13.00 & 24.00 & 2.86 \\
\hline & Preventive behavior & 21.19 & 13.00 & 28.00 & 3.21 \\
\hline & Health habits & 21.31 & 17.00 & 24.00 & 1.93 \\
\hline & Positive mental attitude & 20.88 & 13.00 & 24.00 & 3.01 \\
\hline & Health habits—summarized & 84.50 & 56.00 & 93.00 & 9.61 \\
\hline \multirow{5}{*}{ Males } & Proper eating habits & 21.09 & 16.00 & 24.00 & 2.13 \\
\hline & Preventive behavior & 21.09 & 15.00 & 29.00 & 2.48 \\
\hline & Health habits & 21.69 & 17.00 & 24.00 & 1.89 \\
\hline & Positive mental attitude & 21.09 & 15.00 & 29.00 & 2.40 \\
\hline & Health habits—summarized & 84.97 & 70.00 & 101.00 & 5.82 \\
\hline \multirow{5}{*}{ All participants } & Proper eating habits & 21.10 & 13.00 & 24.00 & 2.46 \\
\hline & Preventive behavior & 21.14 & 13.00 & 29.00 & 2.81 \\
\hline & Health habits & 21.52 & 17.00 & 24.00 & 1.90 \\
\hline & Positive mental attitude & 21.00 & 13.00 & 29.00 & 2.67 \\
\hline & Health habits—summarized & 84.78 & 56.00 & 101.00 & 7.68 \\
\hline
\end{tabular}

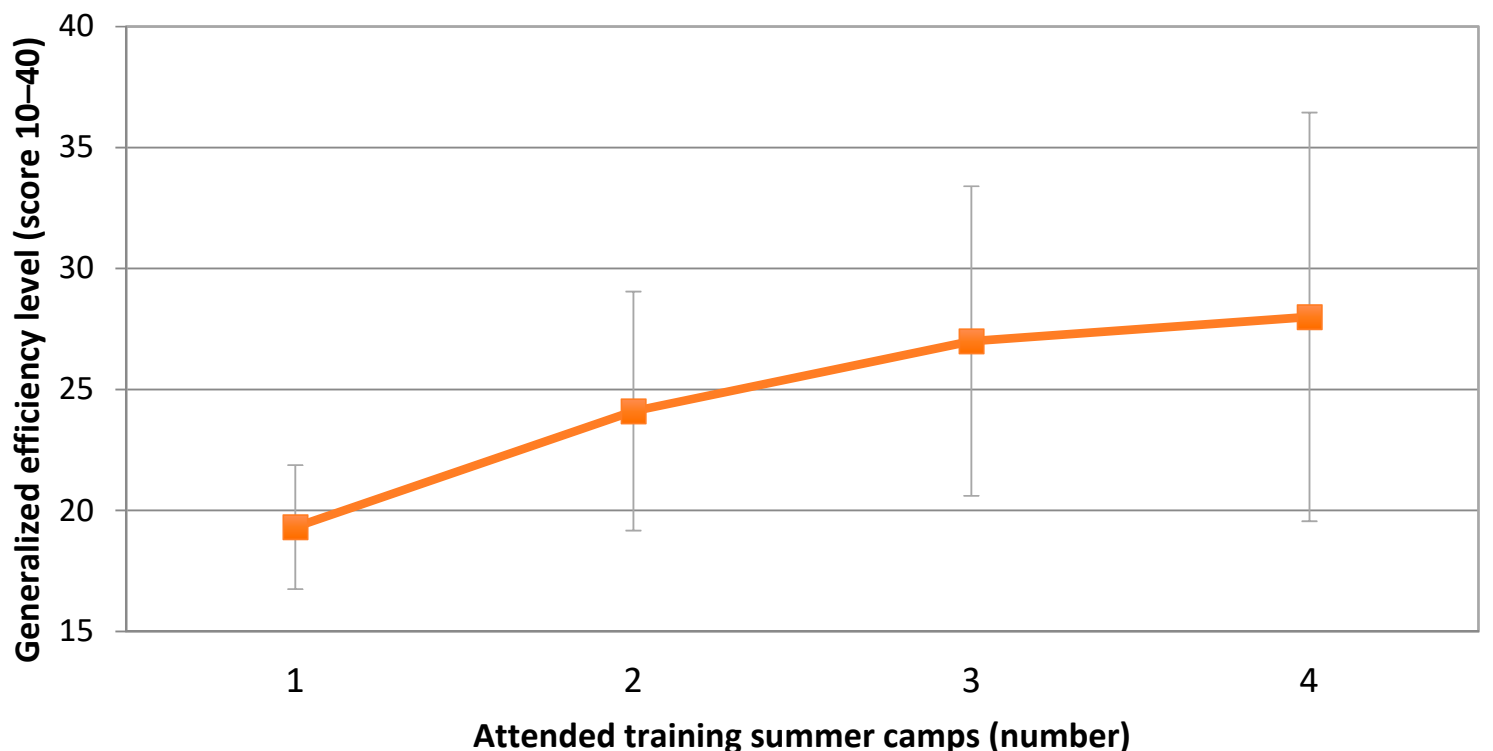

Figure 1. Differences in the Generalized Self-Efficacy indicator depending on the number of attended training summer camps of Taekwon-do athletes $(\mathrm{F}(3.54), p<0.000)$.

The correlation coefficient analysis of both used inventories did show at least a moderate correlation between the health-related behavior and the perception of self-efficacy. No relations were found between the health habits variable and GSE, while the highest score $(r=0.53)$ was revealed between GSE and the preventive behavior (Table 2).

The cluster analysis of tested athletes split the participants into two groups. The second cluster is characterized by the higher GSE values, eating habits, preventive behavior, and mental attitude. The only higher mean score for the first cluster is that of health habits (Table 3). At the same time, the univariate analysis of the presented variables by the specific cluster shows that the health habits indicator values are not significantly different among participants grouped in these clusters. Other variables are significantly different at a level 
of $p<0.01$ (Table 4). The number of participants in the second cluster is much lower, but all cases start with at least two attended camps and higher mean values.

Table 2. Pearson correlation coefficient values of specified variables of health-related categories and Generalized Self-Efficacy indicator $(p<0.05)$.

\begin{tabular}{ccccc}
\hline $\begin{array}{c}\text { Health } \\
\text { Behavior }\end{array}$ & $\begin{array}{c}\text { Proper Eating } \\
\text { Habits }\end{array}$ & $\begin{array}{c}\text { Preventive } \\
\text { Behavior }\end{array}$ & $\begin{array}{c}\text { Health } \\
\text { Habits }\end{array}$ & $\begin{array}{c}\text { Positive Mental } \\
\text { Attitude }\end{array}$ \\
\hline $\begin{array}{c}\text { Generalized } \\
\text { Self-Efficacy }\end{array}$ & 0.49 & 0.53 & 0.07 & 0.42 \\
\hline
\end{tabular}

Table 3. Descriptive statistics of specific clusters revealed in the analysis.

\begin{tabular}{|c|c|c|c|c|c|c|c|c|c|}
\hline \multirow{2}{*}{ Category } & \multirow{2}{*}{ Indicator } & \multicolumn{4}{|c|}{ Cluster $1(\mathrm{~N}=43)$} & \multicolumn{4}{|c|}{ Cluster $2(\mathrm{~N}=15)$} \\
\hline & & Mean & Min & Max & SD & Mean & Min & Max & SD \\
\hline \multirow{4}{*}{$\begin{array}{l}\text { Health behavior } \\
\quad \text { (score 6-24) }\end{array}$} & Proper eating habits & 20.56 & 13.00 & 24.00 & 2.56 & 22.67 & 20.00 & 24.00 & 1.23 \\
\hline & Preventive behavior & 20.35 & 13.00 & 24.00 & 2.52 & 23.40 & 20.00 & 29.00 & 2.35 \\
\hline & Health habits & 21.60 & 17.00 & 24.00 & 1.84 & 21.27 & 17.00 & 24.00 & 2.12 \\
\hline & Positive mental attitude & 20.44 & 13.00 & 24.00 & 2.52 & 22.60 & 17.00 & 29.00 & 2.50 \\
\hline $\begin{array}{l}\text { Cognitive factor } \\
\text { (score 10-40) }\end{array}$ & Generalized Self-Efficacy & 20.05 & 10.00 & 24.00 & 3.12 & 33.93 & 27.00 & 39.00 & 4.23 \\
\hline \multicolumn{2}{|c|}{ Camp attendance } & 1.91 & 1.00 & 4.00 & 0.95 & 2.73 & 2.00 & 4.00 & 0.88 \\
\hline
\end{tabular}

SD—standard deviation, SS—sum of squares.

Table 4. ANOVA analysis findings of specific variables (Health Behavior Inventory and Generalized Self-Efficacy) by categorical factor of cluster groups.

\begin{tabular}{|c|c|c|c|c|c|}
\hline Category & Indicator & Between SS & Within SS & $\mathbf{F}$ & $p$ \\
\hline \multirow{4}{*}{ Health behavior } & Proper eating habits & 44.14 & 316.775 & 7.80 & 0.00 \\
\hline & Preventive behavior & 103.53 & 345.367 & 16.79 & 0.00 \\
\hline & Health habits & 1.27 & 205.212 & 0.35 & 0.56 \\
\hline & Positive mental attitude & 44.27 & 409.879 & 6.05 & 0.01 \\
\hline Cognitive factor & Generalized Self-Efficacy & 2144.56 & 658.84 & 182.28 & 0.00 \\
\hline
\end{tabular}

SS-sum of squares, F-Fisher's statistics, $p$-significance value.

\section{Discussion}

Obtained analysis of the cluster results shows that the attendance in the Taekwon-do summer camps may be a differential factor for the Generalized Self-Efficacy indicator (Figure 1). This could be interpreted from the perspective of the specific goals set in those camps. The willingness to participate in such activities is a sign of the mindset focused on self development within a group of people who share the common goals and worldview, especially connected to martial arts. Therefore, sport practice, in this case a Taekwondo practice, creates specific environmental and social conditions that are suitable for the development of proper health habits [25].

The sense of the effectiveness, as well as other aspects of personal development, involves a certain amount of effort. Participation in more camps means longer training experience. More training experience does not always mean higher scores in the competitions, but long-term practice demands certain fortitude from the individual. The presented results correspond with other studies, where participants express higher GES scores, while also being less mentally devastated after failures, which in turn, could correspond with the long-term practice fortitude. Such a mental attitude of ignoring failure, or the ability to 
withstand certain mental pressure connected with failure, is connected with a higher selfefficacy level or the winner-type personality [26]. Belief in one's own performance could be one of the indicators for the sense of self-esteem. This attitude affects the perception of the task difficulty, as well as handling inconveniences during the task execution [27]. On the contrary, low self-esteem is connected with a worse level of performance of the given tasks [28].

Despite some premises, these psychological indicators vary significantly between the genders of experienced athletes [29], in which the univariate analysis did not show significant differences between genders in this particular case, which facilitates the treatment of the study groups as one. The cluster analysis illustrates that the tested group is mostly divided on the basis of the perception of self-efficacy and most of the health behavior indicators. Despite the differences between the cluster groups, the indicator of health habits was not statistically different. This may indicate that health behavior as a biological aspect of health is common for all participants, but individual participants have a higher mental-related indicator, alongside that of higher self-esteem. The correlation coefficient levels also prove that those three Health Behavior Inventory parts have a moderate relation to the General Self-Efficacy. The lack of dominance of a single factor for the clustering algorithm means that the winner-type perception is a more complex phenomenon and that a person needs more wholesome development to see the inner-self in such a way. The presented results are concurrent with other studies in the health and psychology-based literature. Health behavior patterns are not homogeneous concepts [30-32]. Moreover, self-efficacy is associated with healthy behavior [33].

The effort and conscious role of the undertaken effort is a part of Taekwon-do training. From the basic level of training, skills and performance are verified by participation in sparring and competitions. While being exposed to challenging social circumstances, the facilitation of a pro-social attitude is a normal phenomenon in a Taekwon-do training group. It is a successful form of health preservation by reducing improper health habits [32].

Based on the conducted research, we can assume that Taekwon-do ITF practice is beneficial for developing a high perception of self-efficacy and healthy behavior. The obtained results could be explained in the context of a socio-cognitive model, where the perception level of self-efficacy depends on the previous life experiences. Systematic practice of this form of martial arts allows people to get proper experience, which was proven in the study which indicated that Taekwon-do related experiences enable athletes to regain mental balance faster after unpleasant experiences (67.7\%) [34]. From the biopsychosocial perspective, the process of technique practice should be perceived as a harmonious wholeness. This is a complex and long-lasting process. Therefore, Taekwon-do practice has become an inseparable part of daily life in both the biological and sociological processes.

The limitation of this study is the lack of a control group. However, our conclusions are based on the cluster analysis. After 10 iterations, that algorithm and division of the participants was valid. Tables 3 and 4 refer to this analysis, explaining factors and strength of the analysis. Therefore, instead of having a control group, our analysis divided tested participants based on psychological indicators, and then results were compared to attended camps, which shows that fewer participants placed in Cluster 2 showed a higher mean of the number of attended camps alongside a higher self-efficacy value. We are not putting forward a radical thesis of the number of training camps in our work (as an independent variable) that has an impact on such variables as the feeling of effectiveness and health behavior (as dependent variables). The deliberations were conducted in a much more cautious manner, with the application of the method which is recommended in such cases when the data may be defined as out of focus. Due to this fact, we availed of such definitions in our work as the differentiation of the findings among the people who participated in the training camp many times. Likewise, for this reason, in our calculations the findings were analyzed and subsequently presented in the tables that illustrate the maximization of the variances within the cluster and between the clusters (Table 4). The acquired findings do not authorize us to generalize in terms of the entire population. The significance of 
the findings may be interpreted as the increase in the importance of the arguments in favor of the treatment of training camps away from home, as such a form of activity that may be beneficial for health behavior and the feeling of effectiveness in the following two ways: The first way is, to a certain degree, such a sports trip that may constitute a way to verify the effects of regular training and a fight against your own weaknesses. Between the feeling of effectiveness and health behavior there are positive connections, such as the ability to make intentions come true (e.g., a diet), persistence in the execution of plans (e.g., avoiding certain favored ingredients that do not serve a healthy diet). The second argument relates to the fact that training camps away from home may be treated as such forms of activity that lead to the co-creation of the elements of a lifestyle that combine the social development of practitioners, while also becoming familiar with the culture of the region and development in the sphere of physical culture.

Self-efficacy is one of the factors that affects behavior. With an increased belief in one's own possibilities to solve tasks, there is the motivation to form intentions and undertake action [35-38]. An increase in mental fortitude could also be linked to recommendations for coaches to put emphasis on the development of high determination amongst their students [39].

The obtained results link attendance in training camps with an increase in social and psychological dependencies of the winner-type attitude. This phenomenon could be associated with the term martial arts tourism [40,41]. This term refers to visiting particular places of martial arts practice with famous history, but the aim of such a journey could be perceived in a similar case as in training camps. In both cases, the mental values of trips are of crucial value to a martial arts fighter as a practitioner. Although the spiritual aspect of health is still not recognized as a separate value [42], it could be perceived in the case of martial arts as a changed mental attitude toward the inner-self and habits due to practice. The specificity of spending time focused on practice during training camps could increase the awareness of the proper eating habits, body mass control, the proper amount of sleep, and mindset for overcoming the hardships of daily training. In contrary to the rest of the year and common practice activities, such a distinguishable time of the year could bring stronger stimuli, which brings more decisive changes in the long-term effects. This study's findings widen the knowledge about the phenomenon of martial arts tourism and its psychological values, which have become a subject of interest for researchers in the recent years [21]. This study did not specify the nature of the training camps and trip destinations. Martial arts tourism and training camps could be held in the cradle of Taekwon-do-North Korean regions [43] for the sole purpose of training, to the academic camps of South Korea for academic development [44]. Most studies about martial arts tourism refers to expert level practitioners and some of them have academic degrees. This is one of the first studies in the subject that contains a larger number of participants. This experimental evidence about psychological values of martial arts tourism is a confirmatory factor about the humanistic nature of martial arts and supports the General Theory of Fighting Arts.

\section{Conclusions}

Attendance in the organized forms, such as summer training camps, therefore longer practice, is associated with the increased self-efficacy level of Taekwon-do athletes. The obtained results have shown that the mental indicators are increased due to longer Taekwondo practice, and therefore continuous practice of martial arts could be used as a means of shaping positive health behavior. Therefore, Taekwon-do practice has a positive influence on all aspects of the biopsychosocial model of health. It is possible to presume and indicate certain premises in order to assume that the people who decide to join a training camp that is away from their place of abode, particularly the people who participate multiple times in such a training camp, to a certain extent agree to a certain regime in terms of undertaking an intensified effort, self-discipline, and the continuation of joint work in conditions away from home. Participation in additional forms of activity such as training 
camps is associated with becoming familiar with new places, people, and elements of the culture of the region. In this sense, it is possible to state that participation in these forms of activity, particularly on a regular basis and more frequently than a one-off, is simultaneously a way of spending free time which creates a certain active lifestyle. Martial arts tourism in the sports camp dimension could be perceived as a method of shaping the proper attitude towards challenges, problem-solving tasks, and the mental capacity to cope with failures, which are all an expression of self-efficacy.

Author Contributions: Conceptualization, D.O. and J.W.; Methodology, D.O.; Formal Analysis, D.O., J.W., and D.M.; Investigation, D.O.; Resources, D.O. and J.W.; Data Curation, D.O.; WritingOriginal Draft Preparation, D.O., J.W., and D.M.; Writing-Review and Editing, D.O., J.W., and D.M.; Visualization, D.O., J.W., and D.M.; Supervision, J.W.; Project Administration, J.W.; Funding Acquisition, J.W. All authors have read and agreed to the published version of the manuscript.

Funding: This research received no external funding.

Institutional Review Board Statement: Ethical review and approval were waived for this study, due to type of the experiment, which includes only use of standardized psychological questionnaire. As the study does not include any attributes of medical experiments, the study was conducted according to the guidelines of the Declaration of Helsinki and Ethical Committee protocol was not required.

Informed Consent Statement: Informed consent was obtained from all subjects involved in the study.

Data Availability Statement: The data presented in this study are available on request from the corresponding author.

Conflicts of Interest: The authors declare no conflict of interest.

\section{References}

1. Lehman, B.J.; David, D.M.; Gruber, J.A. Rethinking the biopsychosocial model of health: Understanding health as a dynamic system. Soc. Personal. Psychol. Compass. 2017, 11, 1-17. [CrossRef]

2. Ấlvarez, Ó.S.; Ruiz-Cantero, M.T.; Cassetti, V.; Cofiño, R.; Álvarez-Dardet, C. Salutogenic interventions and health effects: A scoping review of the literature. Gac. Sanit. 2020. [CrossRef] [PubMed]

3. John, J.M.; Haug, V.; Thiel, A. Physical Activity Behavior from a Transdisciplinary Biopsychosocial Perspective: A Scoping Review. Sports Med. Open. 2020, 6, 49. [CrossRef] [PubMed]

4. Bendíková, E.; Dobay, B. Physical and Sport Education as a Tool for Development of a Positive Attitude Toward Health and Physical Activity in Adulthood. Eur. J. Cont. Educ. 2017, 6, 14-21. [CrossRef]

5. Capranica, L.; Chiodo, S.; Tessitore, A. A Multi-dimensional Approach to Support Youth Taekwon-do Athletes TT-A Multidimensional Approach to Support Youth Taekwon-do Athletes. Acta Taekwon-do Martialis Artium 2017, 4, 7.

6. Cho, S.-Y.; So, W.-Y.; Roh, H.-T. The Effects of Taekwon-do Training on Peripheral Neuroplasticity-Related Growth Factors, Cerebral Blood Flow Velocity, and Cognitive Functions in Healthy Children: A Randomized Controlled Trial. Int. J. Environ. Res. Public Health 2017, 14, 454. [CrossRef]

7. Januário, M.S.; Figueiredo, L.S.; Portes, L.L.; Benda, R.N. Effects of Self-Controlled Knowledge of Results on Learning a Taekwon-do Serial Skill. Percept. Mot. Skills 2019, 126, 1178-1194. [CrossRef]

8. Cho, S.-Y.; Roh, H.-T. Taekwon-do Enhances Cognitive Function as a Result of Increased Neurotrophic Growth Factors in Elderly Women. Int. J. Environ. Res. Public Health 2019, 16, 962. [CrossRef] [PubMed]

9. Danyschuk, A.T. The effectiveness of the technology of physical therapy of flat feet in young athletes of all ages by means of taekwon-do. Health Sport. Rehabil. 2019, 5, 16. [CrossRef]

10. Rajan, P.; Tsang, H.W. Martial arts practice in community-based rehabilitation: A review. Int. J. Ther. Rehab. 2015, 22, 31-34. [CrossRef]

11. Akin, M.; Kesilmiş, İ. The effect of blood flow restriction and plyometric training methods on dynamic balance of Taekwon-do athletes. Pedagog. Phys. Cult. Sports 2020, 24, 157-162. [CrossRef]

12. Chung, P.; Ng, G. Taekwon-do training improves the neuromotor excitability and reaction of large and small muscles. Phys. Ther. Sports 2012, 13, 163-169. [CrossRef]

13. Fong, S.S.M.; Tsang, W.W.N.; Ng, G.Y.F. Taekwon-do training improves sensory organization and balance control in children with developmental coordination disorder: A randomized controlled trial. Res. Dev. Disabil. 2012, 33, 85-95. [CrossRef] [PubMed]

14. Leong, H.T.; Fu, S.N.; Ng, G.Y.F.; Tsang, W.W.N. Low-level Taekwon-do practitioners have better somatosensory organisation in standing balance than sedentary people. Eur. J. Appl. Physiol. 2011, 111, 1787-1793. [CrossRef] [PubMed]

15. Wasik, J. Three Areas of Taekwon-do Identification and Practice. Ido Mov. Cult. Martial Arts Anthropol. 2014, 14, 22-26. [CrossRef]

16. Cynarski, W.J. Towards a general theory of fighting arts. Phys. Act. Rev. 2017, 5, 83-90. [CrossRef] 
17. Henderson, K.A.; Whitaker, L.S.; Bialeschki, M.D.; Scanlin, M.M.; Thurber, C. Summer Camp Experiences. J. Fam. Issues 2007, 28, 987-1007. [CrossRef]

18. Akilian, F. Pedagogic and Didactic Skills of Taekwon-do Coaches and its Possible Impact in Selecting Methods to Teach Taekwondo TT-Pedagogic and Didactic Skills of Taekwon-do Coaches and its Possible Impact in Selecting Methods to Teach Taekwon-do. Int. Symp. Taekwon-do Stud. 2017, 2017, 76-77.

19. Cynarski, W.J. Wspótczesne Formy Turystyki Kulturowej; Buczkowska, K., von Rohrscheidt, A.M., Eds.; AWF Poznań: Poznań, Poland, 2009; pp. 346-359.

20. Schwarzer, R.; Mueller, J.; Greenglass, E. Assessment of Perceived General Self-Efficacy on the Internet: Data Collection in Cyberspace. Anxiety Stress Coping 1999, 12, 145-161. [CrossRef]

21. Pawelec, P.; Świder, P.; Cynarski, W.J. Martial Arts Tourism: Meta-Analysis of Publications from 2005-2020. Sustainability 2020, 12, 7069. [CrossRef]

22. Juczyński, Z. Narzędzia Pomiaru w Promocji i Psychologii Zdrowia Towarzystwa Psychologicznego; Pracownia Testów Psychologicznych: Warszawa, Poland, 2009.

23. Wallston, K.A.; Strudler Wallston, B.; DeVellis, R. Development of the Multidimensional Health Locus of Control (MHLC) Scales. Health Educ. Monogr. 1978, 6, 160-170. [CrossRef]

24. Emery, C.A. Considering Cluster Analysis in Sport Medicine and Injury Prevention Research. Clin. J. Sport Med. 2007, 17, 211-214. [CrossRef] [PubMed]

25. Vella, S.A. Mental Health and Organized Youth Sport. Kinesiol. Rev. 2019, 8, 229-236. [CrossRef]

26. Mouloud, K.; El-Kadder, B.A. Self-efficacy, Achievement motivation and Anxiety of Elite Athletes. IOSR J. Sports Phys. Educ. 2016, 3, 45-48. [CrossRef]

27. Beauchamp, M.R. Efficacy Beliefs Within Relational and Group Contexts in Sport. In Social Psychology in Sport; Human Kinetics: Champaign, IL, USA, 2007; pp. 181-193.

28. Bong, M. Academic Motivation in Self-Efficacy, Task Value, Achievement Goal Orientations, and Attributional Beliefs. J. Educ. Res. 2004, 97, 287-298. [CrossRef]

29. Pacesova, P.; Smela, P.; Kracek, S. Personal well-being as part of the quality of life: Is there a difference in the personal well-being of women and men with higher level of anxiety trait regarding their sport activity? Phys. Act. Rev. 2019, 7, 201-208. [CrossRef]

30. Laaksonen, M.; Luoto, R.; Helakorpi, S.; Uutela, A. Associations between Health-Related Behaviors: A 7-Year Follow-up of Adults. Prev. Med. 2002, 34, 162-170. [CrossRef]

31. Thorpe, R.J., Jr.; Kennedy-Hendricks, A.; Griffith, D.M.; Bruce, M.A.; Coa, K.; Bell, C.N.; Young, J.; Bowie, J.V.; LaVeist, T.A. Race, Social and Environmental Conditions, and Health Behaviors in Men. Fam. Community Health 2015, 38, 297-306. [CrossRef]

32. Origua Rios, S.; Marks, J.; Estevan, I.; Barnett, L.M. Health benefits of hard martial arts in adults: A systematic review. J. Sports Sci. 2018, 36, 1614-1622. [CrossRef]

33. Sheeran, P.; Maki, A.; Montanaro, E.; Avishai-Yitshak, A.; Bryan, A.; Klein, W.M.P.; Miles, E.; Rothman, A.J. The impact of changing attitudes, norms, and self-efficacy on health-related intentions and behavior: A meta-analysis. Health Psychol. 2016, 35, 1178-1188. [CrossRef]

34. Ortenburger, D.; Wasik, J.; Gora, T.; Tsos, A.; Bielikowa, N. Taekwon-do: A chance to develop social skills. Ido Mov. Cult. 2017, 17, 14-18. [CrossRef]

35. Cynarski, W.J.; Yu, J.H. Ethical values in jujutsu of Japanese origin. Phys. Act. Rev. 2021, 9, 33-39. [CrossRef]

36. Sari, I. An Investigation of Imagery, Intrinsic Motivation, Self-efficacy and Performance in Athletes. Anthropologist 2015, 20, 675-688. [CrossRef]

37. Kmiecik, A.; Bakota, D.; Płomiński, A. The level of mood regulation in practicing hatha yoga in the background of people who do not practice this physical activity. Phys. Act. Rev. 2020, 8, 95-103. [CrossRef]

38. Culpepper, D.; Killion, L. Effects of exercise on risk-taking. Phys. Act. Rev. 2017, 5, 1-5. [CrossRef]

39. Juwono, I.D.; Szabo, A. The efficacy of Self Determination Theory-based interventions in increasing students' physical activity: A systematic review. Phys. Act. Rev. 2020, 8, 74-86. [CrossRef]

40. Cynarski, W.J.; Swider, P. The journey to the cradle of martial arts: A case study of martial arts tourism. Ido Mov. Cult. 2017, 17, 24-33. [CrossRef]

41. Cynarski, W.J. Ideological conditioning of martial arts training. Phys. Act. Rev. 2018, 6, 14-21. [CrossRef]

42. Dhar, N.; Chaturvedi, S.; Nandan, D. Spiritual health scale 2011: Defining and measuring 4 dimension of health. Indian J. Community Med. 2011, 36, 275-282. [CrossRef]

43. Cynarski, W.J.; Johnson, J.A. North Korea's emerging martial arts tourism: A Taekwon-Do case study. Int. J. Cult. Tour. Hosp. Res. 2020, 14, 667-680. [CrossRef]

44. Johnson, J.A. Taekwon-do as an Academic Field of Study for Non-Koreans: An Unconventional and Extreme Form of Martial Arts Tourism. Sustainability 2021, 13, 3124. [CrossRef] 